\title{
Tobacco use among transgender and gender non-binary youth in Brazil
}

\author{
Uso de tabaco entre jovens transgêneros e não-binários do Brasil
}

Anna Martha Vaitses Fontanari (https://orcid.org/0000-0002-1457-3884) ${ }^{1}$
Siobhan Churchill (https://orcid.org/0000-0002-3348-473X) ${ }^{2}$
Maiko Abel Schneider (https://orcid.org/0000-0002-8722-1388) ${ }^{1}$
Bianca Soll (https://orcid.org/0000-0001-5488-2027) ${ }^{1}$
Angelo Brandelli Costa (http://orcid.org/0000-0002-0742-8152) ${ }^{3}$
Maria Inês Rodrigues Lobato (https://orcid.org/0000-0003-3925-4051) ${ }^{1}$
${ }^{1}$ Departamento de Psiquiatria, Hospital de Clínicas de Porto Alegre, Universidade Federal do Rio Grande do Sul. R. Ramiro Barcelos 2350, Santa Cecilia. 90035-903 Porto Alegre RS Brasil.

annamarthavf@gmail.com

${ }^{2}$ Western University.

London ON Canadá.

${ }^{3}$ Pontifícia Universidade

Católica do Rio Grande do

Sul. Porto Alegre RS Brasil.
Abstract Transgender and gender non-binary youth are particularly vulnerable to tobacco smoking and susceptible to smoking adverse health outcomes. That is, they are in special risk to start smoking and, after starting, they may face worse outcomes when comparing to their cisgender peers. Therefore, the present study aims to evaluate factors associated with tobacco use among transgender and gender non-binary youth. Brazilian youth aged 16 to 25 who identify as transgender or gender non-binary answered an online questionnaire. Poisson regression with robust variance was run to predict smoking cigarettes based on individual and environmental factors. $14.1 \%$ of 206 youth reported smoking cigarettes daily, whereas $9.3 \%$ of participants reported smoking e-cigarettes occasionally. Drug use, lack of social support, deprivation, discrimination, the wait for medical gender-affirming procedures and being outside school were associated with smoking cigarettes. Contextual and individual factors should be further explored in causal analysis and taken into consideration when planning smoking prevention and cessation interventions for transgender and gender non-binary youth.

Key words Transgender youth, Gender diversity, Youth, Tobacco smoking
Resumo Jovens transgêneros e não-binários são particularmente vulneráveis ao tabagismo e suscetíveis a seus malefícios a saúde. Ou seja, esses grupos estão em especial risco para começar a fumar e, após o início, tendem a apresentar resultados piores quando comparados a seus pares cisgêneros. Sendo assim, o presente estudo tem como objetivo avaliar fatores associados ao uso do tabaco em jovens transgêneros e não-binários. Jovens brasileiros, com idade entre 16 e 25 anos, que se identificam como transgêneros ou não-binários responderam um questionário on-line. Uma Regressão de Poisson com variância robusta foi realizada para predizer o consumo de cigarros com base em fatores individuais e ambientais. 14,1\% de 206 jovens relataram fumar cigarros diariamente, enquanto 9,3\% dos participantes revelaram fumar cigarros eletrônicos ocasionalmente. Uso de drogas, falta de suporte social, experiências de privação, discriminação, espera para procedimentos médicos de afirmação de gênero e evasão escolar foram associados ao consumo de cigarros entre jovens transgêneros e não-binários brasileiros. Sendo assim, os fatores individuais e contextuais citados devem receber especial enfoque no planejamento de intervenções de prevenção $e$ interrupção do tabagismo voltados a jovens transgêneros e não-binários brasileiros.

Palavras-chave Transgêneros, Diversidade de gênero, Juventude, Tabagismo 


\section{Introduction}

Transgender and gender non-binary youth face many adversities related to stigma and discrimination. In fact, they endure a broad spectrum of gender-related discrimination that, in Brazil, may present as more subtle barriers (such as difficulty accessing general health care ${ }^{1}$ ) as well as very explicit violence (for example, homicide ${ }^{2}$ ). Chronic stress as a result of marginalization increases the prevalence of depressive symptoms, psychological distress, suicide, substance abuse and smoking among this population ${ }^{3,4}$.

Currently, smoking cigarettes is the leading cause of preventable disease and death worldwide 5 . The smoking epidemic is on a decline in developed countries while rapidly on the rise in developing countries ${ }^{6}$. In Brazil, an estimated $13.6 \%$ of all adult deaths are attributable to smoking-related chronic airway obstruction, lung cancer, ischemic heart disease and cerebrovascular disease ${ }^{7}$. Smoking tobacco is an especially concerning issue among adolescents and young adults since experimenting with cigarettes in youth increases the odds of addiction and, thus, continuing to smoke in adulthood ${ }^{8}$. Besides, early smoking increases risk of using other psychoactive substances ${ }^{9}$ and aggravates the health impacts of tobacco ${ }^{10}$. For example, smokers who started smoking before 15 years of age present twice the risk of lung cancer when compared with those who had started after 20 years of age ${ }^{10}$. Smoking may be especially deleterious for transgender and gender non-binary youth who seek gender-affirming medical treatment, such as hormonal therapy and surgery, because it increases risk of thromboembolic events ${ }^{11}$ and worse surgical outcomes ${ }^{12}$.

To date, there is scarce data concerning cigarette smoking among transgender and gender non-binary youth worldwide ${ }^{13,14}$; regarding Brazilian transgender and gender non-binary youth, there is no known published data. An American retrospective cross-sectional analysis of electronic health records involving 46 transgender patients ages 12 to 29 found that $21.74 \%$ of them were current smokers ${ }^{13}$. Another US study, encompassing 2,369 transgender students, found that transgender adolescents exhibited the highest prevalence of substance use (including smoking and vaping) compared to cisgender males and females, including cisgender Lesbian, Gay and Bisexual (LGB) students ${ }^{3}$.

The disparities in smoking rates between gender and sexuality minorities and cisgender heterosexual peers may be explained by several factors: from personal characteristics (i.e., other substance use) and interpersonal relationships (i.e., social support) to environmental (i.e., discrimination and deprivation) and structural issues (i.e., security and lack of health care access). A systematic review, that assessed papers focusing on tobacco use among sexual minorities, listed personal characteristics, such as depression, alcohol use and stress as possible reasons for these differences ${ }^{15}$. Considering interpersonal relationships, a qualitative US study, which interviewed LGBT youth, found that stress to "fit in" and peer pressure was the most frequently cited reasons for smoking ${ }^{16}$. Furthermore, youth that reported rejection by family and peers, as well as lack of support, use more tobacco ${ }^{3,16}$. Environmental and structural factors were also determinants to cigarette use. Among them, victimization ${ }^{15}$ and waiting more time to access medical gender-affirming procedures (such as hormone therapy) ${ }^{13}$ were associated with a higher prevalence of smoking. For example, two recent reviews showed that people identified as travestis are in a severe vulnerable situation regarding their health. One of the reviews ${ }^{17}$ showed that often doctors do not touch their bodies during physical examination, which can weak the physitian-patient bond and cause withdraw from health services. Furthermore, travestis report fear of being mistreated in health services, which favors non-use. In addition, not observing the social name causes great discomfort. It is also common for health professionals to associate the image of the travesti person with HIV infection. Thus, any and all symptoms always refer to the possibility of infection and may cause iatrogenesis or delay a diagnosis. Finally, the review concludes that the fact that travestis leave their consultations "depressed" or "down" reveals that there is no adequate reception by health professionals. The other review ${ }^{18}$ showed that a process of institutional discrimination in relation to this group remains in Brazilian health services and that scientific production in this field needs to be deepened.

Electronic cigarettes (or e-cigarettes) are battery-powered nicotine delivery devices ${ }^{19}$. E-cigarettes were first released in 2004 with the promise of reducing tobacco risks ${ }^{20}$. Since then, their popularity has increased rapidly, while issues concerning their safety and efficacy for smoking cessation remain controversial ${ }^{20}$. For this reason, the WHO Framework Convention on Tobacco Control recommends avoiding the promotion of 
e-cigarettes, especially among youth ${ }^{21}$. Accordingly, the Brazilian Health Regulatory Authority Agency, in 2009, introduced policy banning the sale, import and advertisement of e-cigarettes ${ }^{22}$. However, there is evidence that e-cigarettes are being illegally sold in Brazil2 ${ }^{23}$. Furthermore, recent research shows that $4.6 \%$ of 721 Brazilian students had used e-cigarettes in the past six months ${ }^{23}$. In contrast to cigarettes, e-cigarettes are predominately utilized by more educated Brazilian youth who perceive e-cigarettes to be harmless ${ }^{23}$.

The present study aims to evaluate factors associated with tobacco use among transgender and gender non-binary youth.

\section{Methods}

\section{Theoretical framework}

The Bioecological Model for Human Development emphasizes development as systemic and dynamic, meaning that it is composed of many different trajectories depending on interactions between persons and their immediate environments ${ }^{24}$. Considering the mature version of Bronfenbrenner's ecological theory, this interaction is a combination of four components: Process, Person, Context and Time (PPCT) ${ }^{24}$. Accordingly, this study evaluates the Process of starting to smoke cigarettes and e-cigarettes. It includes Person as features that may influence smoking, such as previous history of substance, as well as demographic characteristics and deprivation experiences. The study design presents a particular interest in assessing Context, mainly because public policies may have a more critical impact on changing environment than directly affecting one`s personality. Thus, Micro and Mesosystems included information concerning family and school relationships, whereas Exo and Macrosystems encompassed discrimination experiences and social support (Figure 1).

While the PPCT model may help to explain smoking among adolescents in the general population, Minority Stress Theory clarifies the higher smoking rates found among transgender youth. The Minority Stress Model was designed to explain the higher prevalence of mental disorders among LGB populations when compared to heterosexual groups ${ }^{25}$, but it was also applied for transgender persons ${ }^{26}$. Briefly, Meyer proposed three main processes that affect LGB populations: external events that occur as a result of one's mi- nority status, the anticipation that these external stressors will happen, and internalized homophobia. These three processes result in worse mental health outcomes. Considering Minority Stress Theory, being transgender may affect both Person and Context Bronfenbrenner's categories. Accordingly, being perceived as transgender (a Demand characteristic) may affect interactions, for example, aggravating school interactions with both peers and teachers ${ }^{27}$. Furthermore, Resources characteristics may be affected by internalized transphobia, since it has been associated with poorer coping skills ${ }^{28}$ and low self-esteem ${ }^{29}$. Regarding Context, both victimization and stigma anticipation highly vary according to macrosystems. That is, living in communities with high structural stigma enhances sexual minority violent deaths rates ${ }^{30}$.

\section{Participants}

Participants were recruited by convenience sampling through a Facebook announcement that was available from February to April 2018. The advertisement was visible for Facebook users who lived in Brazil; were between 16 and 25 years old; and "liked" or joined groups or events related to transsexuality. Facebook statistics suggested that $1.37 \%$ of the impressions directed volunteers to the main page of the study.

\section{Ethical considerations}

The project was approved by the Ethical Committee and Research Commission of Universidade Federal do Rio Grande do Sul Psychology Institute. Volunteers were informed about the research objectives, and the inexistence of direct benefices for joining the survey, before signing the consent. Confidentiality and anonymity were assured, as well as the possibility to withdraw at any time.

\section{Measures}

The survey was modeled after the TransYouth CAN! Project, a cohort study that will document sociodemographic and health-related characteristics of Canadian transgender and gender non-binary youth and their parents/caregivers. The procedure for cross-cultural adaptation of the instrument for Brazilian populations was based on Borsa et al. ${ }^{31}$.

The present study assessed modifiable (study, place of residence, drug and alcohol use) and 


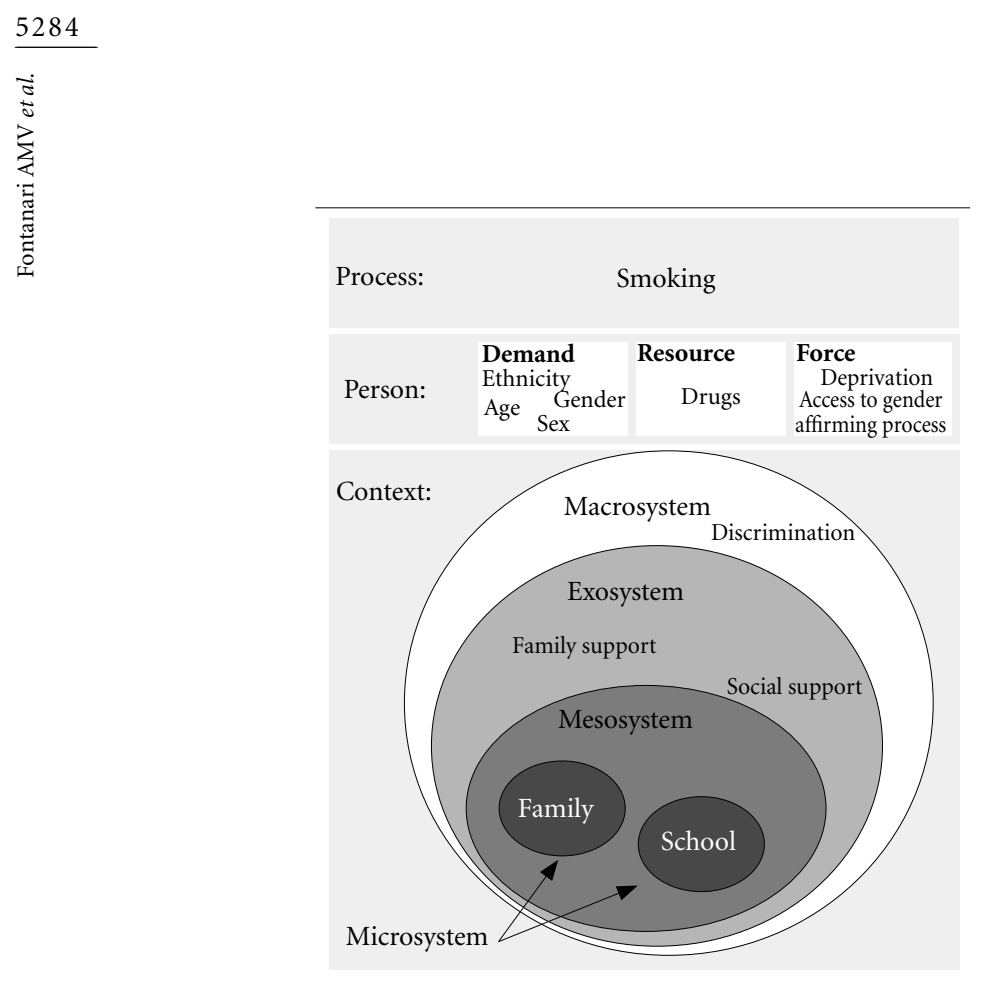

Figure 1. Factors associated with smoking cigarettes among transgender and gender non-binary youth.

Source: Elaborated by the authors.

non-modifiable (age, ethnicity) individual-level factors, as well as interpersonal relationships (social and familial support), environmental issues (discrimination and deprivation) and structural issues (insecurity and lack of health care access).

\section{Process}

Regarding smoking, participants answered whether they currently smoke both cigarettes and e-cigarettes (or vaping), choosing between "yes" or "no" options.

\section{Person}

Gender identity was assessed by the two-step method $^{32}$. The first question concerns the sex assigned at birth and the second question asks how the participants describe their gender identity. Participants were included if they reported a gender different from the sex assigned to them at birth. Based on their self-reported gender identity, participants were re-categorized as young transgender women, young transgender men and gender non-binary youth. Young transgender women were those who were designated as male at birth but identified as women, transgender women or travestis (cultural-specific term). Young transgender men were those who were designated as female at birth but identified as men or transgender men. Finally, gender non-binary youth were those who identified with a gender identity outside the binaries (male and female), such as queer, non- binary, a-gender, and others.

In order to evaluate substance use, participants answered whether, in the last 12 months, they had used any substance, including cannabis and medications that were not prescribed.

The Deprivation Scale was developed by TransYouth CAN! Team in order to verify whether transgender youth had access to basic needs. It is composed of five questions each one with a 5-point Likert scale from "always" to "never". For example, "in the last 12 months, how often did you have access to proper seasonal clothing (such as coat, hat, boots, etc.) if and when you need them?".

Access to medical gender-affirming processes was measured by asking participants who reported the desire to access gender-affirming procedures whether they were still waiting to access or have already accessed medical services that provide, for example, hormone therapy.

\section{Context}

To assess family cohesion, transgender youth were asked to choose, using a scale of one to five, from "my family works well together" to "we really need help". This question is part of Self-Report Family Instrument ${ }^{33}$.

The MOS Social Support Scale is composed of four domain $s^{34}$ : emotional/informational support, tangible support, affectionate support and positive social interaction. All questions were answered with a five-item Likert-type scale. The emotional/informational support subscale included eight questions concerning having someone to talk and share personal problems. The tangible support subscale includes four questions about actually having help in case of disease. The affectionate support subscale is composed of three items involving having someone that shows love and make them feel wanted. Finally, the positive social interaction subscale includes three items concerning having someone to share happy moments with.

The discrimination scale was developed by the TransYouth CAN! Team. It is composed of nine questions evaluating previous experiences of discrimination, for example, "because of who you are, have you been called names or heard/ saw your identity used as an insult?". A four-point Likert-type scale was used to answer each question, ranging from "never" to "yes, many times in the past year". 
SPSS software version 18.0 was used for data management and statistical analyses. Ethnicity, age, gender identity, the Brazilian region, substance use, and family structure were transformed into dummy variables, whereas security, social support, deprivation and discrimination were included as continuous variables. Shapiro-Wilks test of normality was utilized to assess the normality of continuous variables. When the assumption of normality was confirmed, t-tests were applied. When either one or both of group's data was not normally distributed, or the groups' sizes differed significantly, Mann-Whitney U Tests were utilized.

Since the prevalence of smoking cigarettes was higher than $10 \%$ among transgender and gender non-binary youth, the odds ratio from a logistic regression model would overestimate the risk ratio. Thus, Poisson regression with robust variance was applied to estimate crude prevalence ratios $(\mathrm{PR})$ for smoking cigarettes, with individual and contextual factors as independent variables $^{35}$. The first set of models considered all independent variables individually to produce crude PRs, while the second model included all individual- and contextual-level factors to produce adjusted PRs.

\section{Results}

\section{General characteristics}

A total of 206 participants were included. Among them, 97 (47.1\%) were identified as transgender boys, $43(20.9 \%)$ as transgender girls, and $66(32.0 \%)$ as gender non-binary youth. The mean age of participants was 18.6. More than a half $(62.0 \%)$ of transgender and gender non-binary youth were currently in school, either in middle/high school or undergraduate programs. They were mainly Caucasian and located in Southern Brazil. Concerning general characteristics, transgender and gender non-binary youth who smoked were older $(\mathrm{p}=.015)$ and were more frequently currently in school $(\mathrm{p}=.014)$ com-

pared to transgender and gender non-binary youth who did not smoke. It is noteworthy that, as described in Table 1, no statistically significant difference was found among transgender boys, transgender girls and gender non-binary youth concerning smoking status. For more detail on general characteristics see Table 2.

\section{Smoking prevalence among transgender youth}

Fourteen percent of transgender and gender non-binary youth reported smoking cigarettes daily, whereas $9.3 \%$ of participants referred to smoke e-cigarettes occasionally. Only one participant reported smoking e-cigarettes daily in contrast with 29 transgender and gender non-binary youth who smoked cigarettes daily.

\section{Factors associated with smoking cigarettes}

As shown in Table 2, participants who smoked cigarettes reported more experiences with discrimination $(\mathrm{p}=.006)$ and deprivation $(\mathrm{p}<.001)$, as well as reported waiting for gender-affirming procedures ( $\mathrm{p}=.024)$ and using drugs more frequently in the last 12 months $(\mathrm{p}<.001)$ compared to transgender youth who did not smoke cigarettes.

Poisson regression with robust variance was run to predict smoking cigarettes based on individual-level factors (age, study, ethnicity, drug use and Brazil region) and contextual factors (discrimination, security, social support, deprivation, family support and previous access to medical gender-affirming process). As shown in Figure 2, a generally less supportive Context was associated with an elevated prevalence of smoking cigarettes compared to those with a more supportive contextual environment. More precisely, lack of social support ( $\mathrm{PR}=1.004,95 \% \mathrm{CI} 1.000$ 1.007), deprivation ( $\mathrm{PR}=1.125,95 \% \mathrm{CI} 1.034$ $1.225)$, discrimination ( $\mathrm{PR}=1.011,95 \% \mathrm{CI} 1.001$ $1.022)$, the wait for medical gender-affirming procedures ( $\mathrm{PR}=1.203,95 \% \mathrm{CI} 1.001-1.431)$ and being outside school ( $\mathrm{PR}=1.146,95 \% \mathrm{CI} 1.005$ 1.307) were associated with smoking cigarettes. Among individual-level variables, only drug use was associated with smoking $(\mathrm{PR}=1.172,95 \% \mathrm{CI}$ 1.051-1.307) (Table 3).

\section{Discussion}

To date, the present research is the first to assess the associations of Person (age, ethnicity, study, 
Table 1. Smoking cigarettes and e-cigarettes rates among transgender boys, transgender girls and gender nonbinary youth.

\begin{tabular}{|c|c|c|c|c|c|c|c|c|c|}
\hline & \multicolumn{2}{|c|}{ Total } & \multicolumn{2}{|c|}{ Transgender boys } & \multicolumn{2}{|c|}{ Transgender girls } & \multicolumn{2}{|c|}{$\begin{array}{c}\text { Gender non-binary } \\
\text { youth }\end{array}$} & \multirow[t]{2}{*}{$\mathbf{p}$} \\
\hline & $\mathbf{N}(\%)$ & 95\%CI & $\mathbf{N}(\%)$ & 95\%CI & $\mathbf{N}(\%)$ & 95\%CI & $\mathbf{N}(\%)$ & 95\%CI & \\
\hline $\mathrm{N}$ & & 206 & & 97 & & 43 & & 66 & \\
\hline $\begin{array}{l}\text { Cigarette } \\
\text { smoking }\end{array}$ & & & & & & & & & $.614^{\mathrm{a}}$ \\
\hline Yes & $29(14.1)$ & $9.6-19.6$ & $13(13.4)$ & $7.3-21.8$ & $8(18.6)$ & $8.4-33.3$ & $8(12.1)$ & $5.4-22.5$ & \\
\hline No & $177(85.9)$ & $80.4-90.4$ & $84(86.6)$ & $78.2-92.7$ & $35(81.4)$ & $66.6-91.6$ & $58(87.9)$ & $77.5-94.6$ & \\
\hline $\begin{array}{l}\text { E-cigarette } \\
\text { smoking }\end{array}$ & & & & & & & & & --- \\
\hline Yes & $19(9.3)$ & $5.7-14.1$ & $13(13.5)$ & $7.3-21.8$ & $3(7.0)$ & $1.5-19.1$ & $3(4.5)$ & $0.9-12.7$ & \\
\hline No & $186(90.7)$ & $85.9-94.3$ & $86(86.5)$ & $80.6-94.2$ & $40(93.0)$ & $80.9-98.5$ & $63(95.5)$ & $87.3-99.1$ & \\
\hline
\end{tabular}

Source: Elaborated by the authors.

Table 2. General characteristics.

\begin{tabular}{|c|c|c|c|c|c|c|c|}
\hline \multirow{3}{*}{ Covariates } & \multirow{2}{*}{\multicolumn{2}{|c|}{ Total $(\mathrm{N}=206)$}} & \multicolumn{4}{|c|}{ Smoking cigarettes } & \multirow{3}{*}{$\mathbf{p}$} \\
\hline & & & \multicolumn{2}{|c|}{ Yes $(\mathrm{N}=29)$} & \multicolumn{2}{|c|}{ No $(\mathrm{N}=177)$} & \\
\hline & $\begin{array}{l}\text { Mean } \\
\text { N (\%) }\end{array}$ & $\begin{array}{c}\text { SD } \\
95 \% \mathrm{CI}\end{array}$ & $\begin{array}{l}\text { Mean } \\
\text { N (\%) }\end{array}$ & $\begin{array}{c}\text { SD } \\
95 \% \mathrm{CI}\end{array}$ & $\begin{array}{l}\text { Mean } \\
\text { N (\%) }\end{array}$ & $\begin{array}{c}\text { SD } \\
95 \% \mathrm{CI}\end{array}$ & \\
\hline Age & 18.6 & 2.5 & 19.4 & 2.0 & 18.5 & 2.5 & $.015^{\mathrm{a}}$ \\
\hline Studying (no) & $79(38.0)$ & $31.7-45.4$ & $18(22.8)$ & $14.1-33.6$ & $61(77.2)$ & $66.4-85.9$ & $.014^{\mathrm{c}}$ \\
\hline Ethnicity (non-white) & $61(38.1)$ & $23.5-36.4$ & $11(18.0)$ & $9.4-30.0$ & $50(82.0)$ & $70.0-90.6$ & $.829^{c}$ \\
\hline Region from Brazil (Southern) & $153(75.4)$ & $67.7-80.1$ & $23(15.0)$ & $9.8-21.7$ & $130(85.0)$ & $78.3-90.2$ & $.816^{\mathrm{c}}$ \\
\hline Discrimination & 26.5 & 6.7 & 29.6 & 5.6 & 25.9 & 6.7 & $.006^{\mathrm{a}}$ \\
\hline Security & 10.8 & 4.3 & 10.3 & 4.8 & 10.4 & 4.3 & $.922^{\mathrm{b}}$ \\
\hline Social support & 64.6 & 20.1 & 65.8 & 20.0 & 64.4 & 20.1 & $.723^{\mathrm{a}}$ \\
\hline Deprivation & 4.8 & 1.1 & 5.6 & 1.6 & 4.7 & 0.9 & $.000^{\mathrm{a}}$ \\
\hline Family support (bad) & $85(47.0)$ & $34.5-48.3$ & $14(16.5)$ & $9.3-26.1$ & $71(83.5)$ & $73.9-90.7$ & $.677^{c}$ \\
\hline Alcohol abuse (yes) & $23(11.1)$ & $7.2-16.3$ & $6(26.1)$ & $10.2-48.4$ & $17(73.9)$ & $51.6-89.8$ & $.114^{\mathrm{c}}$ \\
\hline Drug use (yes) & $108(51.9)$ & $45.4-59.4$ & $27(25.0)$ & $17.2-34.3$ & $81(75.0)$ & $65.7-82.8$ & $.000^{c}$ \\
\hline $\begin{array}{l}\text { Waiting to access to medical } \\
\text { gender affirming process }\end{array}$ & $139(72.0)$ & $60.6-73.8$ & $15(10.8)$ & $6.2-17.2$ & $124(89.2)$ & $82.8-93.8$ & $.024^{\mathrm{c}}$ \\
\hline
\end{tabular}

${ }^{a}$ Mann-Whitney test; ${ }^{b}$ t test; ${ }^{c}$ Chi-square test.

Source: Elaborated by the authors.

place of residence and drug use) and Context factors (social and familial support, discrimination and deprivation, insecurity and lack of healthcare access) with smoking among transgender and gender non-binary youth. Furthermore, it is the only study that attempts to estimate the prevalence of smoking (both e-cigarettes and cigarettes, respectively) among transgender and gender non-binary youth who live in a developing country. While the observed prevalence and associations should be considered exploratory given the lack of population-based sample, they remain valuable given the paucity of data on Brazilian transgender and gender non-binary youth and the practical impediments to capturing such a group with population-based sampling.

According to the current study, in comparison to Brazilian students captured by Barreto et al. ${ }^{36}$, transgender youth presented a 2.3 times higher prevalence of tobacco use $(14.1 \%, 6.1 \%)$. 


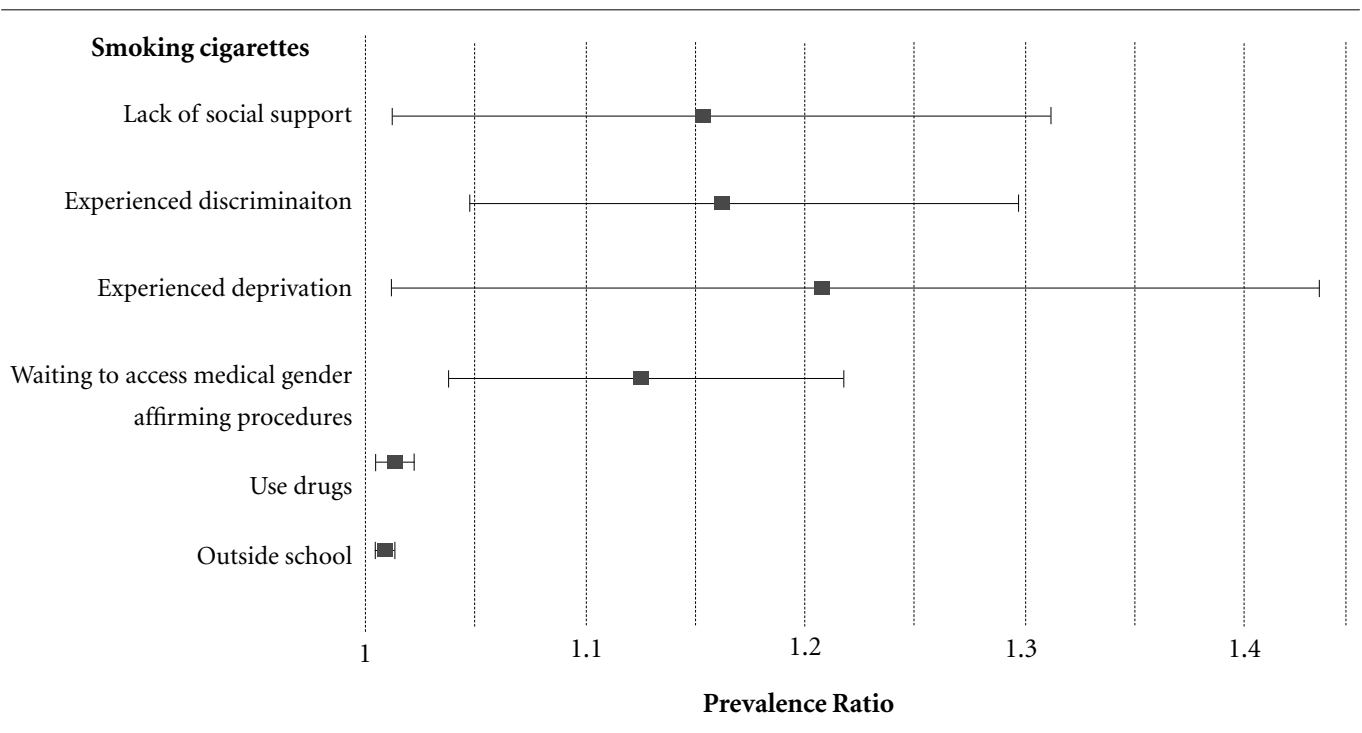

Figure 2. Prevalence ratio of factors associated with smoking cigarettes.

Source: Elaborated by the authors.

Table 3. Poisson regressions with robust variance predicting smoking cigarettes based on Person factors (age, study, ethnicity, gender identity, drug use and Brazil region) and Context factors (discrimination, security, social support, deprivation, family support and previous access to medical gender affirming process).

\begin{tabular}{|c|c|c|c|c|c|c|c|c|}
\hline \multicolumn{9}{|c|}{ Person } \\
\hline & $\mathbf{p}$ & PR & \multicolumn{2}{|c|}{ 95\%CI } & $\mathbf{p}$ & aPR & \multicolumn{2}{|c|}{ 95\%CI } \\
\hline Age & .043 & 1.018 & 1.001 & 1.036 & .613 & .992 & .962 & 1.023 \\
\hline Studying (no) & .012 & 1.144 & 1.030 & 1.271 & .041 & 1.146 & 1.005 & 1.307 \\
\hline Ethnicity (non-white) & .761 & .981 & .870 & 1.107 & .163 & .905 & .786 & 1.041 \\
\hline Region from Brazil (Southern) & .576 & 1.031 & .927 & 1.147 & .671 & 1.030 & .900 & 1.179 \\
\hline Drug use (yes) & .000 & 1.246 & 1.141 & 1.361 & .004 & 1.172 & 1.051 & 1.307 \\
\hline \multicolumn{9}{|l|}{ Gender identity } \\
\hline Gender diverse youth & .809 & .987 & .890 & 1.095 & .931 & .994 & .865 & 1.141 \\
\hline Transgender women & .449 & 1.053 & .921 & 1.205 & .362 & .934 & .806 & 1.082 \\
\hline \multicolumn{9}{|c|}{ Context } \\
\hline & $\mathbf{p}$ & PR & \multicolumn{2}{|c|}{ 95\%CI } & $\mathbf{p}$ & aPR & \multicolumn{2}{|c|}{ 95\%CI } \\
\hline Discrimination & .002 & 1.010 & 1.004 & 1.017 & .039 & 1.011 & 1.001 & 1.022 \\
\hline Security & .927 & .999 & .988 & 1.011 & .482 & 1.007 & .987 & 1.027 \\
\hline Social support & .717 & 1.000 & .998 & 1.003 & .029 & 1.004 & 1.000 & 1.007 \\
\hline Deprivation & .000 & 1.099 & 1.043 & 1.158 & .006 & 1.125 & 1.034 & 1.225 \\
\hline Family support (bad) & .582 & 1.030 & .928 & 1.143 & .241 & .921 & .803 & 1.057 \\
\hline $\begin{array}{l}\text { Waiting to access to medical gender } \\
\text { affirming process }\end{array}$ & .038 & 1.142 & 1.008 & 1.294 & .037 & 1.203 & 1.011 & 1.431 \\
\hline
\end{tabular}

Source: Elaborated by the authors.

While these two samples cannot be compared directly, previous literature on Minority Stress Theory and substance use among transgender youth supports the finding that this population may engage more frequently in smoking than non-transgender youth. According to Minority Stress Theory, belonging to a minority group generates chronic exposure to three principal 
forms of stress $s^{25,26,37}$. First, transgender youth suffer from explicit discrimination, such as verbal harassment or physical assault. For example, according to the Trans Murder Monitoring Project, Brazil has one of the highest numbers of transgender homicides in the world ${ }^{2}$. Also, among LGBTQ+ populations, transgender people are the most frequent victims of hate crimes, including severe bodily injury and homicide ${ }^{38}$. Second, transgender youth are in constant anticipation of adverse external events, which leads to avoidance of specific situations. For example, Brazilian transgender and gender non-binary people that reported previous experiences of discrimination from health care providers avoided seeking medical assistance, even during emergency situations ${ }^{1}$. Finally, experiencing internalized transphobia may cause, for example, fear of disclosing their gender identities and sexual orientations to health care professionals ${ }^{39}$. Similarly, the present study shows that minority-stressors such as suffering discrimination and lack of social support, as well as facing barriers to access gender-affirming medical care, may increase the prevalence of cigarette smoking among transgender youth.

Factors at the structural level appeared to have a stronger influence on smoking than individual-level factors. These factors included having difficulty to access gender-affirming medical care and not attend school. In accordance, current data show that transgender youth who experienced incongruent puberty presented higher rates of anxiety and depression, and gender-affirming medical assistance attenuates these symptoms $\mathrm{s}^{40-42}$. Also supporting the results, transgender students have reported high levels of school victimization ${ }^{43,44}$, leading to depression, self-harm, and suicidal ideation ${ }^{45}$. Since smoking has been listed as a stress-related coping strategy ${ }^{46}$, the higher prevalence of smoking among transgender and gender non-binary youth who experience more structural barriers is not surprising. The absence of governmental strategies to address these structural barriers is, however, outstanding. According to the Resolution No 8/2013 of the Brazilian Federal Council of Medicine, outpatient clinics specialized on gender identity and behavior can provide care to children and adolescents exclusively as research projects. Even though many outpatient clinics support adults, currently, there are only two hospitals able to provide hormonal suppression and therapy to Brazilian transgender youth: Gender Identity Program (PROTIG) at Hospital de Clínicas de Porto Alegre (HCPA) and Ambulatory of Gender Identity and Sexual Orientation (AMTIGOS) at Hospital de Clínicas de São Paulo (HCFMUSP), respectively from South and Southern Brazil. Regarding strategies to alleviate transgender youth victimization in schools, in 2004, a federal government program named "Brazil Without Homophobia" was launched. Producing and distributing educational materials on gender identity and sexual orientation diversity in schools was among its main objectives. Nevertheless, the material was only finalized in 2011 and, in response to pressure from conservative sectors of society, had its release postponed. To date, it has not been launched.

Populations victimized with chronic stress, such as African Americans, exhibit higher smoking incidence, greater tobacco dependence ${ }^{47}$ and poorer cessation outcomes ${ }^{48}$. Although no data is focusing on interventions specially developed for transgender and gender non-binary youth, it is safe to assume that - since they also use smoking to manage discrimination, low social support, and insufficient material resources they would endure some similar difficulties with other groups victimized by minority stress. The Last Drag was an American seven-session group workshop tailored for LGBT smokers. The results of this intervention were promising: $60 \%$ of participants were smoke-free at the end of the intervention, and $36 \%$ remained smoke-free six months post-intervention ${ }^{49}$. Transgender and gender non-binary youth, however, do not exclusively carry "transgender" status, they also face issues that are common for adolescents and young adults. US adolescents aged 18 to 25 smoke more than any other age group ${ }^{50}$ and, even though more than half want to quit or reduce smoking ${ }^{51}$, only a few are successful ${ }^{51}$. A randomized controlled trial, including 164 young adults (from 18 to 25 years old), evaluated the effectivity of a text messaging-based smoking cessation program ${ }^{52}$. They also obtained satisfactory results: intervention participants (39\%) were more likely than the control group $(21 \%)$ to have quit at four weeks post intervention ${ }^{52}$. It is clear that interventional programs should be adjusted according to the main factors affecting smoking among transgender and gender non-binary youth: deprivation, discrimination, difficulty in accessing specialized care and not attending school.

The present research is the first to evaluate the prevalence of e-cigarette use among transgender and gender non-binary youth from a developing country. Nine percent of transgender 
and gender non-binary youth occasionally use e-cigarettes; thus, Brazilian transgender and gender non-binary youth presented 2.0 times higher rate of smoking e-cigarettes when compared to Brazilian youth. Similarly, it has been shown that US transgender adults have a higher risk than cisgender adults to use novel tobacco products, such as e-cigarettes ${ }^{14}$. Factors associated with e-cigarette smoking appear to differ from those associated with cigarette smoking, including a low perception of harmfulness and a higher educational level ${ }^{25}$.

This study has some limitations. First, and most important, the recruitment strategy was convenience sampling. Although being the first Brazilian research to evaluate smoking among transgender and gender non-binary youth, adolescents and young adults from outside Southern Brazil are underrepresented. Furthermore, this sample is composed of transgender and gender non-binary youth able to access the internet and more marginalized groups may not have had the opportunity to access the online questionnaire. Therefore, the sample does not represent the Brazilian transgender and gender non-binary youth population; consequently, it is not possible to definitively assess smoking prevalence. However, this study had the advantage of including participants without requiring parental consent, meaning that transgender and gender non-binary youth with and without parental support for their gender identity were likely included. Second, the cross-sectional design and small sample size precluded the authors from assessing causality between the given risk factors and smoking. The present study should be considered exploratory, and if possible supplemented by more extensive, population-based studies. It is the authors' hope that this study may serve as a starting point for further research on the causes of smoking among transgender and gender non-binary youth in developing countries.

\section{Conclusion}

This study provides the first exploratory evidence that smoking prevalence may be elevated among Brazilian transgender and gender non-binary youth compared to population-based estimates from the general population. Furthermore, minority stressors such as lack of access to gender-affirming medical care may contribute to this elevated prevalence. Future studies should continue to investigate these potential differences, acknowledging that stressors and determinants of smoking may be distinct for LGB youth compared to gender non-binary youth. Furthermore, research should focus on developing and evaluating smoking prevention and cessation interventions designed specifically for transgender and gender non-binary adolescents and young adults - that is, programs that take into account population-specific barriers to health including deprivation, discrimination, and lack of access to necessary medical care.

\section{Collaborations}

AMV Fontanari and $\mathrm{AB}$ Costa designed the work, analysed data from the included articles, and drafted the manuscript. S Churchill analysed the data and drafted the current manuscript. MA Schneider, B Soll and MIR Lobato drafted the current manuscript. All authors approved the submitted version and are personally accountable for their own contributions, as well as for the accuracy of the results provided here. 


\section{Acknowledgments}

We thank the Health Equity and Epidemiology Research Group (HEER) for multiple, and very useful, insights. We also thank TransYouth CAN! Team for sharing their survey. We also acknowledgments both CNPq and CAPES for funding this research through scholarships.

\section{Funding}

Conselho Nacional de Desenvolvimento Científico e Tecnológico (CNPq) and Coordenação de Aperfeiçoamento de Pessoal de Nível Superior (CAPES) provided financial support though scholarships.

\section{References}

1. Costa AB, Rosa Filho HT, Pase PF, Fontanari AMV, Catelan RF, Mueller A, Cardoso D, Soll B, Schwarz K, Schneider MA, Gagliotti DAM, Saadeh A, Lobato MIR, Nardi HC, Koller SH. Healthcare needs of and access barriers for Brazilian transgender and gender diverse people. J Immigr Minor Heal 2016; 20(1):115123.

2. Balzer C, Hutta JS, Adrián T, Hyndal P. Transrespect versus transphobia worldwide: A comparative review of the human-rights situation of gender-variant/trans people. Berlin: TGEU; 2012.

3. Coulter RWS, Bersamin M, Russell ST, Mair C. The effects of gender- and sexuality-based harassment on lesbian, gay, bisexual, and transgender substance use disparities. J Adolesc Heal 2018; 62(6):688-700.

4. Veale JF, Watson RJ, Peter T, Saewyc EM. Mental health disparities among canadian transgender youth. $J$ Adolesc Heal 2017; 60(1):44-49.

5. Jha P, Peto R. Global effects of smoking, of quitting, and of taxing tobacco. N Engl J Med 2014; 370:69-68.

6. Prokhorov AV, Winickoff JP, Ahluwalia JS, Ossip -Klein D, Tanski S, Lando HA, Moolchan ET, Muramoto M, Klein JD, Weitzman M, Ford KH, Tobacco Consortium, American Academy of Pediatrics Center for Child Health Research. Youth tobacco use: a global perspective for child. Pediatrics 2006; 118(3):890-905.

7. Corrêa PCRP, Barreto SM, Passos VMA. Smoking-attributable mortality and years of potential life lost in 16 Brazilian capitals, 2003: a prevalence-based study. BMC Public Health 2009; 13(9):1-13.

8. Brook DW, Brook JS, Zhang C, Whiteman M, Cohen P, Finch SJ. Developmental trajectories of cigarette smoking from adolescence to the early thirties: Personality and behavioral risk factors. Nicotine Tob Res 2008; 10(8):1283-1291.

9. Barreto SM, Giatti L, Casado L, Moura L De, Crespo C. Contextual factors associated with smoking among Brazilian adolescents. J Epidemiol Community Heal 2012; 66:723-730.

10. Peto R, Darby S, Deo H, Silcocks P, Whitley E, Doll R. Smoking, smoking cessation, and lung cancer in the UK since 1950: combination of national statistics with two case-control studies. BMJ 2000; 321:323-329.

11. Wierckx K, Elaut E, Declercq E, Heylens G, De Cuypere G, Taes Y, Kaufman JM, T'Sjoen G. Prevalence of cardiovascular disease and cancer during cross-sex hormone therapy in a large cohort of trans persons: A case-control study. Eur J Endocrinol 2013; 169(4):471478.

12. Goddard JC, Vickery RM, Qureshi A, Summerton DJ, Khoosal D, Terry TR. Feminizing genitoplasty in adult transsexuals: Early and long-term surgical results. BJU Int 2007; 100(3):607-613.

13. Menino DD, Katz-Wise SL, Vetters R, Reisner SL. Associations between the length of time from transgender identity recognition to hormone initiation and smoking among transgender youth and young adults. Transgender Heal 2018; 3(1):82-87.

14. Buchting FO, Emory KT, Kim Y, Fagan P, Vera LE, Emery S. Transgender use of cigarettes, cigars, and e-cigarettes in a national study. Am J Prev Med 2017; 53(1):el-e7. 
15. Blosnich J, Lee JGL, Horn K. A systematic review of the aetiology of tobacco disparities for sexual minorities. Tob Control 2014; 22(2):66-73.

16. Remafedi G. Lesbian, gay, bisexual, and transgender youths: Who smokes, and why? Nicotine Tob Res 2007; 9(1):65-71.

17. Carvalho LBP, Chazan ACS. The Access of Transsexuals and Crossdressers to the Primary Health Care: an integrative review. Rev Bras Med Família Comunidade 2019; 14(41):1795.

18. Rocon PC, Wandekoken KD, Barros MEB, Duarte, MJO, Sodré, F. Access to health by the transsexual population in brazil: between the lines of the integrative review. Trab Educ Saude 2020; 18(1):e0023469.

19. Cobb NK, Byron MJ, Abrams DB, Shields PG. Novel nicotine delivery systems and public health: the rise of the "e-cigarette". Am J Public Heal 2010; 100(12):2340-2342.

20. Chapman SLC, Wu L-T. E-cigarette prevalence and correlates of use among adolescents versus adults: A review and comparison. J Psychiatr Res 2015; 54:4354.

21. World Health Organization (WHO). WHO Framework Convention on Tobacco Control. Geneva: WHO; 2003

22. Brasil. Ministério da Saúde (MS). Agência Nacional de Vigilância Sanitária (ANVISA). Resolução no 46, de 28 de agosto de 2009. Proíbe a comercialização, a importação e a propaganda de quaisquer dispositivos eletrônicos para fumar, conhecidos como cigarro eletrônico. Diário Oficial da União; 2009.

23. Cavalcante TM, Szklo AS, Perez CA, Thrasher JF, Szklo M, Ouimet J, Gravely S, Fong GT, Almeida LM. Electronic cigarette awareness, use, and perception of harmfulness in Brazil: findings from a country that has strict regulatory requirements. Cad Saude Publica 2017; 33(3):138-147.

24. Bronfenbrenner U. Making Human Beings Human: Bioecological Perspectives on Human Development. Thousand Oaks: Sage; 2005.

25. Meyer IH. Minority stress and mental-health in gay men. J Health Soc Behav 1995; 36(1):38-56.

26. Hendricks ML, Testa RJ. A conceptual framework for clinical work with transgender and gender nonconforming clients: An adaptation of the minority stress model. Prof Psychol Res Pract 2012; 43(5):460-467.

27. Greytak EA, Kosciw JG, Diaz EM. Harsh Realities: The Experiences of Transgender Youth in Our Nation's Schools. New York: GLSEN; 2009.

28. Mizock L, Mueser KT. Employment, mental health, internalized stigma, and coping with transphobia among transgender individuals. Psychol Sex Orientat Gend Divers 2014; 1(2):146-158.

29. Austin A, Goodman R. The impact of social connectedness and internalized transphobic stigma on self-esteem among transgender and gender non-conforming adults. J Homosex 2017; 64(6):825-841.

30. Hatzenbuehler ML, Bellatorre A, Lee Y, Finch BK, Muennig P, Fiscella K. Structural stigma and all-cause mortality in sexual minority populations. Soc Sci Med 2014; 103:33-41.
31. Borsa JC. Cross-Cultural Adaptation and Validation of Psychological Instruments: Some Considerations. Padeia 2012; 22(53):423-432.

32. Sausa LA, Sevelius J, Keatley J, Iñiguez JR, Reyes M. Policy Recommendations for Inclusive Data Collection of Trans People in HIV Prevention, Care \& Services. San Francisco: University of California; 2009.

33. Beavers R, Hampson RB. The Beavers systems model of family functioning. Assoc Fam Ther 2000; 22:128143.

34. Sherbourne CD, Stewart AL, Corporation TR, Street M, Monica S. The MOS social support survey. Soc Sci Med 1991; 32(6):705-714.

35. Barros AJ, Hirakata VN. Alternatives for logistic regression in cross-sectional studies: an empirical comparison of models that directly estimate the prevalence ratio. BMC Med Res Methodol 2003; 13:1-13.

36. Barreto ISM, GiattiII L, Oliveira-Campos M, Andreazzi MA, Malta DC. Experimentation and use of cigarette and other tobacco products among adolescents in the Brazilian state capitals (PeNSE 2012). Rev Bras Epidemiol 20140 17(Supl. 1):62-76.

37. Meyer IH. Prejudice, social stress, and mental health in lesbian, gay, and bisexual populations: Conceptual issues and research evidence. Psychol Bull 2003; 129(5):674-697.

38. Calaf PP, Bernardes GC, Rocha GS. Relatório sobre violência homofóbica no Brasil: Ano de 2011. Brasília: Secretaria de Direitos Humanos da Presidência; 2012.

39. Albuquerque GA, Garcia CL, Quirino GS, Alves MJH, Belém JM, Figueiredo FWS, Paiva LS, Nascimento VB, Maciel ÉS, Valenti VE, Abreu LC, Adami F. Access to health services by lesbian, gay, bisexual, and transgender persons: systematic literature review. BMC Int Health Hum Rights 2016; 16:2.

40. Kuvalanka KA, Weiner JL, Mahan D. Child, family, and community transformations: Findings from interviews with mothers of transgender girls. J GLBT Fam Stud 2014; 10(4):354-379.

41. de Vries ALC, McGuire JK, Steensma TD, Wagenaar ECF, Doreleijers TAH, Cohen-Kettenis PT. Young adult psychological outcome after puberty suppression and gender reassignment. Pediatrics 2014; 134(4):696-704.

42. Olson KR, Durwood L, DeMeules M, McLaughlin KA. Mental health of transgender children who are supported in their identities. Pediatrics 2016; 137(3):e20153223.

43. Day JK, Perez-Brumer A, Russell ST. Safe schools? Transgender youth's school experiences and perceptions of school climate. J Youth Adolesc 2018; 47:17311742.

44. Grossman AH, Haney AP, Edwards P, Alessi EJ, Ardon $\mathrm{M}$, Howell TJ. Lesbian, gay, bisexual and transgender youth talk about experiencing and coping with school violence: A qualitative study. J LGBT Youth 2009; 6(1):24-46

45. Almeida J, Johnson RM, Corliss HL, Molnar BE, Azrael D. Emotional distress among LGBT youth: The influence of perceived discrimination based on sexual orientation. J Youth Adolesc 2009; 38(7):1001-1014. 
46. Liautaud MM, Leventhal AM, Pang RD. Happiness as a buffer of the association between dependence and acute tobacco abstinence effects in African American smokers. Nicotine Tob Res 2018; 20(10):1215-1222.

47. Branstetter SA, Mercincavage M, Muscat JE. Predictors of the nicotine dependence behavior time to the first cigarette in a multiracial cohort. Nicotine Tob Res 2014; 17(7):819-824.

48. Feigelman W, Gorman B, Feigelman W, Gorman B. Toward explaining the higher incidence of cigarette smoking among black Americans. J Psychoactive Drugs 1989; 21(3):299-305.

49. Eliason MJ, Dibble SL, Gordon R, Soliz GB. The last drag: An evaluation of an LGBT-specific smoking intervention. J Homosex 2012; 59(6):864-878.

50. CDC. Vital signs: current cigarette smoking among adults aged $\geq 18$ years with mental illness. MMWR Morb Mortal Wkly Rep 2010; 59(35):1135.

51. Reeder AI, Williams S, McGee R, Poulton R. Nicotine dependence and attempts to quit or cut down among young adult smokers. N Z Med J 2001; 114(1139):403.

52. Ybarra ML, Holtrop JS, Prescott TL, Rahbar MH, Strong D. Pilot RCT results of stop my smoking USA: A text messaging - based smoking cessation program for young adults. Nicotine Tob Res 2013; 15(8):13881399.

Article submitted 08/02/2019

Approved 20/12/2019

Final version submitted 22/12/2019

Chief editors: Romeu Gomes, Antônio Augusto Moura da Silva 